\title{
Landslide susceptibility assessment by using a neuro-fuzzy model: a case study in the Rupestrian heritage rich area of Matera
}

\author{
F. Sdao, D. S. Lioi, S. Pascale, D. Caniani, and I. M. Mancini \\ School of Engineering, University of Basilicata, viale dell' Ateneo Lucano n. 10, 85100, Italy \\ Correspondence to: F. Sdao (sdao.francesco@gmail.com)
}

Received: 5 May 2012 - Published in Nat. Hazards Earth Syst. Sci. Discuss.: -

Revised: 8 January 2013 - Accepted: 14 January 2013 - Published: 15 February 2013

\begin{abstract}
The complete assessment of landslide susceptibility needs uniformly distributed detailed information on the territory. This information, which is related to the temporal occurrence of landslide phenomena and their causes, is often fragmented and heterogeneous. The present study evaluates the landslide susceptibility map of the Natural Archaeological Park of Matera (Southern Italy) (Sassi and area Rupestrian Churches sites). The assessment of the degree of "spatial hazard" or "susceptibility" was carried out by the spatial prediction regardless of the return time of the events. The evaluation model for the susceptibility presented in this paper is very focused on the use of innovative techniques of artificial intelligence such as Neural Network, Fuzzy Logic and Neuro-fuzzy Network. The method described in this paper is a novel technique based on a neuro-fuzzy system. It is able to train data like neural network and it is able to shape and control uncertain and complex systems like a fuzzy system. This methodology allows us to derive susceptibility maps of the study area. These data are obtained from thematic maps representing the parameters responsible for the instability of the slopes. The parameters used in the analysis are: plan curvature, elevation (DEM), angle and aspect of the slope, lithology, fracture density, kinematic hazard index of planar and wedge sliding and toppling. Moreover, this method is characterized by the network training which uses a training matrix, consisting of input and output training data, which determine the landslide susceptibility. The neuro-fuzzy method was integrated to a sensitivity analysis in order to overcome the uncertainty linked to the used membership functions. The method was compared to the landslide inventory map and was validated by applying three methods: a ROC (Receiver Operating Characteristic) analysis, a confusion matrix and a SCAI method. The developed neuro-fuzzy method showed a good performance in the determination of the landslide susceptibility map.
\end{abstract}

\section{Introduction}

Basilicata Region (Southern Italy) is, for geological, geomorphological, climatic and seismic reasons, one of the most landslide prone areas of the Mediterranean basin regions, which is characterized by landslides of different types, in which mechanisms of evolution and processes of erosion are intensity selective (Caniani et al., 2008; Pascale et al., 2010, 2012; Polemio and Sdao, 1996, 1998; Gullà and Sdao, 2001; De Bari et al., 2011). In some areas of Basilicata, the landslides are so intense and widespread that they sometimes generate serious damage to people and properties. In recent years, geomorphological studies conducted by the authors showed that many archaeological sites in Basilicata, especially those falling in the Apennines areas, are the sign of a widespread and intense landslide activity, which is affecting and damaging the valuable testimony of historic and archaeological representations. Examples of similar situations can be found in the archaeological areas of: in the archaeological areas of "Rossano di Vaglio" (Sdao and Simeone, 2007), in "Satriano di Lucania" and in a rupestrian area of Matera, where many medieval sights are suffering from a serious state of collapse due to landslides (Sdao et al., 2009; Cotecchia and Grassi, 1997). Numerous studies can be found in the literature regarding the assessment of landslide susceptibility. For example, Oh et al. (2011) applied an adaptive neurofuzzy system (ANFIS) to map the landslide susceptibility (Oh et al., 2011; Gemitzi et al., 2010; Vahidnia et al., 2010). Neuro-fuzzy networks are systems which originate from the union of neural networks and fuzzy inference. The neurofuzzy networks (Masi et al., 2012) are based on fuzzy logic (Zadeh, 1965). This theory was developed for the first time in 1965 by Zadeh and it is now used in various sectors. It was initially constructed to modify the binary logic concept and to bring it to the human way of thinking. Fuzzy logic 
abandons the bivalence true-false and known paradoxes of Boolean logic. Fuzzy logic, neural networks and genetic algorithms are artificial intelligence techniques. They are used in industrial and scientific applications. In particular, adaptive fuzzy inference and neural network methods are able to easily manage the fuzzy rules and to reduce the artifices of the fuzzy and neural models (Iyatomi and Hagiwara, 2004). A neuro-fuzzy analysis compared with a neural analysis does not provide very different results, as evaluated and analyzed by Vieira et al. (2004). The scientific literature has various applications of neuro-fuzzy models from the classical management of humanoid robots that will replace humans in hazardous work, to the medical or service fields (Duško and Miomir, 2003). Neuro-fuzzy networks have also been used in the study of solar time series (Attia et al., 2005) and in the assessment of noise in workplaces (Zaheeruddin, 2006). The neuro-fuzzy networks have been used to determine and define a satisfactory method for real-time control of road intersections as well as for technological-industrial applications (Henry et al., 1998). The seismic events classification has been addressed with the aid of a neuro-fuzzy network, considering some specific parameters for each event (Muller et al., 1998). The daily capacity of a karst aquifer in south-west France was evaluated by applying a neuro-fuzzy and neural model; the comparison showed that the neuro-fuzzy model has a better performance (Kurtulus and Razack, 2010). The evaluation at the regional scale of groundwater vulnerability is a problematic issue; thus, several studies have been carried out to address this problem. In fact, Dixon (2005) evaluated the vulnerability with a neuro-fuzzy analysis and GIS applications. The author carried out a sensitivity analysis, which assessed that the neuro-fuzzy models are sensitive to the form of fuzzy sets, to the fuzzy set number, to the nature of the weights of the rules and validation techniques used during the learning processes. Neuro-fuzzy models are appropriate for the management of imprecise data on a continental and regional scale, and they are to be used in a larger framework of GIS, remote sensing and solute transport modelling with mechanistic, stochastic and functional models. Other authors (Tutmez et al., 2006) developed a neuro-fuzzy model for assessing the water quality in relation to its electrical conductivity. In particular, an adaptive system neuro-fuzzy inference (ANFIS) for the model is the relation between the main cations dissolved in groundwater and the electrical conductivity used. The ANFIS model overcomes the more traditional methods of electrical conductivity modelling based on the total dissolved solids in water. In 2009, Kholghi and Hosseini (2009) applied the neuro-fuzzy model and the kriging method for the water level assessment, in the Qazvin plain (Iran), in areas where no data were available. The neurofuzzy models manage the uncertainty and lack of data well. The use of neuro-fuzzy networks in geology revealed to be advantageous in comparison to neural networks (Caniani et al., 2008) and fuzzy logic (Ercanoglu and Temiz, 2011; Ercanoglu and Gokceoglu, 2004) because they can reduce the

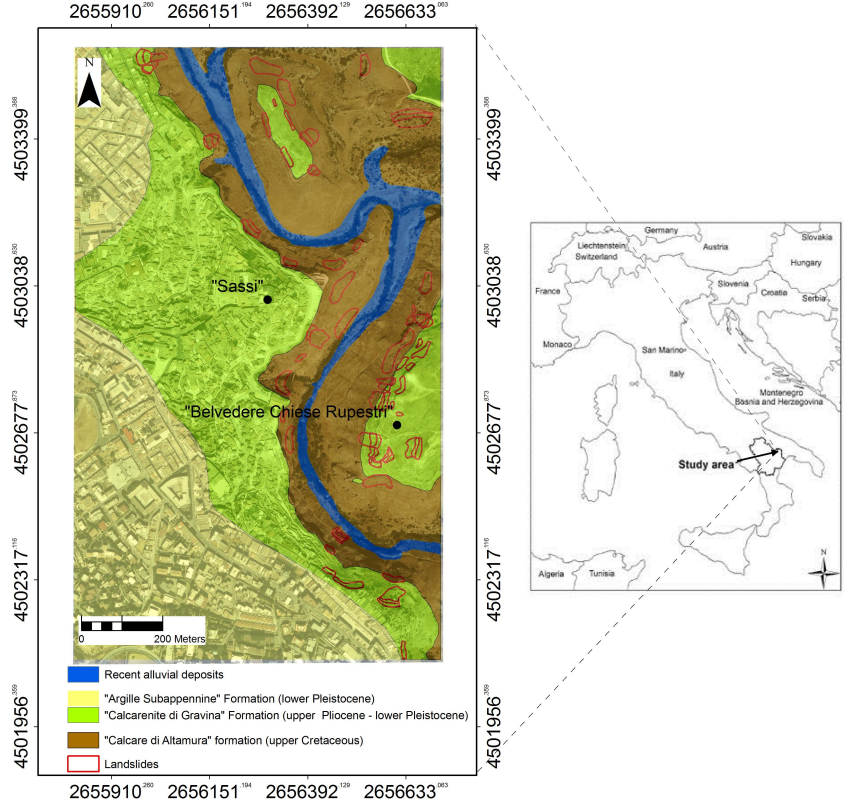

Fig. 1. Geology and geomorphology map of the site Rupestrian Heritage Rich Area of Matera (Basilicata Region, Southern Italy).

uncertainty. In the present study, in fact, the landslide hazard of the Natural Archaeological Park of Matera (Southern Italy) was assessed by developing an innovative adaptative neuro-fuzzy inference system, ANFIS.

\section{Geological, geomorphological and historical aspects of the study area}

\subsection{Geological and geomorphological framework of the study area}

The Matera territory is located between the Apulian foreland and Bradanic foredeep. In the study area, at the top of the foredeep succession, can be found: the "Argille subappennine" formation (lower Pleistocene) and "Calcarenite di Gravina" formation (lower Pleistocene-upper Pliocene), lying in discordance on the "Calcare di Altamura" foreland formation (upper Cretaceous) (Fig. 1). This is a transgressive geological contact well marked and generally tilted about $8^{\circ}-$ $12^{\circ}$ towards WNW.

The "Calcare di Altamura" formation (upper Cretaceous) outcrops in the lower part of the slopes and is characterized by SW-dipping depositional surfaces with a dip angle of about $5^{\circ}-10^{\circ}$. It is constituted by a monotonous succession of micritic limestone, packstone and wackestone with abundant marine Rudiste remains. These terrains are generally well stratified and usually affected by a pervasive fracturing.

The "Calcarenite di Gravina" formation (upper Pliocene - lower Pleistocene) has a medium thickness of about $40 \mathrm{~m}$ 


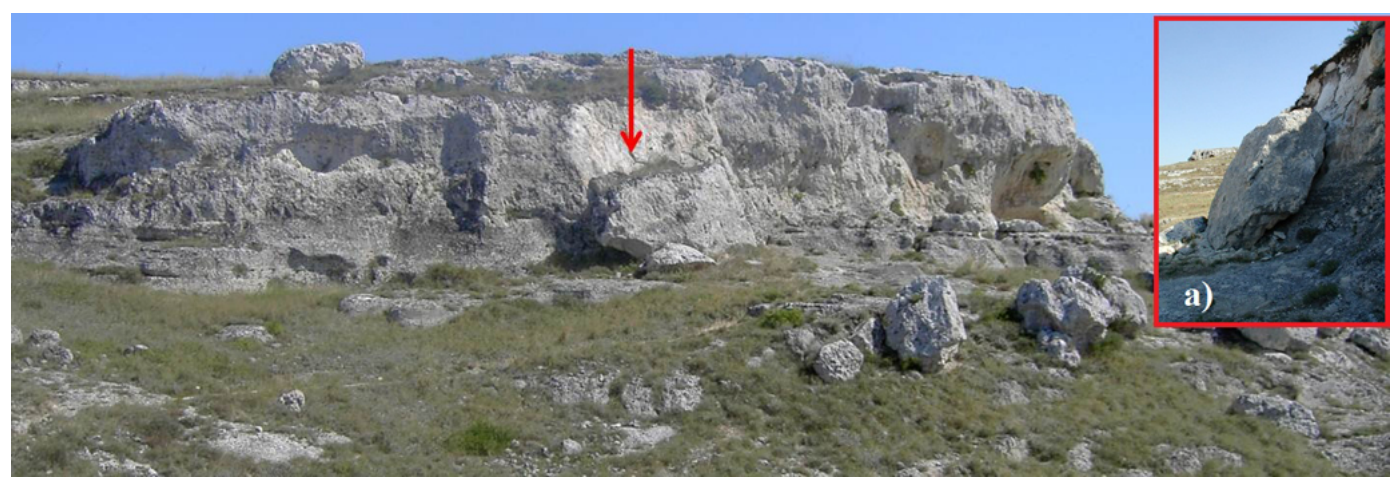

Fig. 2. Location of sliding of rock blocks.

and it is composed of bioclasts and terrigenous limestone fragments. In this formation, it is possible to distinguish two members: one litho-clastic with a terrigeneous origin and a second one bioclastic. This formation is characterized by SW-dipping depositional surfaces with a low dip angle and it is hardly fractured. These calcarenites, cemented and thickened at varying degrees, are stratified in beds and layers with horizontal or slightly tilted positions.

These calcarenites are composed of an intense and widespread fracturing, generated by families of discontinuity variously oriented and often intersected between them. The whole rock settlement is widely affected by evident signs and geomorphological effects generated by landslides in rock: such as toppling and sliding blocks (Fig. 2).

In fact, Fig. 2 shows the entire rock settlement affected by evident signs and geomorphological effects generated by fast landslides in rock, due to rock falls, toppling and sliding blocks.

These landslides particularly affect calcarenitic rocks and are characterized by

- evident detachments with a complex shape, imposed at cracks or intersections of different structural discontinuities;

- rock blocks in a precarious stability state, delimited by open discontinuity or collapsed on the slope below;

- accumulate debris generated by the continuous and rapid morpho-gravitational dynamics characterizing this area.

In many cases, along the entire edge of the ravine, it is possible to observe open discontinuity crests, irrefutable signs of ongoing morphogenetic dynamics.

These effects, due to planar and wedge rock fall phenomena, are probably caused by stratigraphy, lithological characters, different cohesion levels, pervasive jointing, and layers attitude. In order to analyze the fracturing characteristics, the survey was comprised of a data collection (about 250 measures) and the descriptions of surface discontinuity characteristics (opening, spacing and fracture condition).
In particular, landslide scarps and detachment are evident in the central and southern sector of the investigated site. They are largely present on structural discontinuities with a high angle oriented about $210^{\circ} \mathrm{N}$ and $300^{\circ} \mathrm{N}$ circumscribing significant rock blocks.

Recent studies, which used the kinematic stability analysis (Matheson, 1983, 1989; Hudson and Harrison, 1993) showed a high susceptibility to the instability of the site (Sdao et al., 2009). These stability analyses highlighted that:

- the entire site is significantly prone to landslides of rock wedges and direct toppling, controlled by the main discontinuity families, with particular reference to the breaks with attitudes of $\mathrm{N} 51^{\circ} / 68^{\circ}, \mathrm{N} 209^{\circ} / 69^{\circ}$, $\mathrm{N} 272^{\circ} / 63^{\circ}$;

- the areas show that the most marked fall in safety hazards is located in the southern sector of the investigated site.

The kinematic analysis of the potential instability conditions of the investigated area was conducted using the method proposed by Matheson $(1983,1989)$, and partially revised by Hudson and Harrison (1993). This is a method of kinematic analysis that uses only a few geometric and spatial arrangement parameters can determine the movement of rock blocks bounded by flat and infinitely continuing discontinuities, without any reference to the producing forces. Therefore, this type of analysis is integrated by the shear strength developing along the discontinuity planes, represented by the friction angle.

The method allows us to identify which families of discontinuity surfaces, characterized by some genetically primary or secondary parameters, could be potential detachment surfaces of the rock blocks. The types of kinematic movements identified by this analysis are planar sliding, wedge sliding and tilting of rock blocks.

The potential instability conditions of these areas are also confirmed by GPS measurements, which were performed on a network consisting of 10 markers, distributed along the edge of the ravine and conducted in the period 2002-2004 


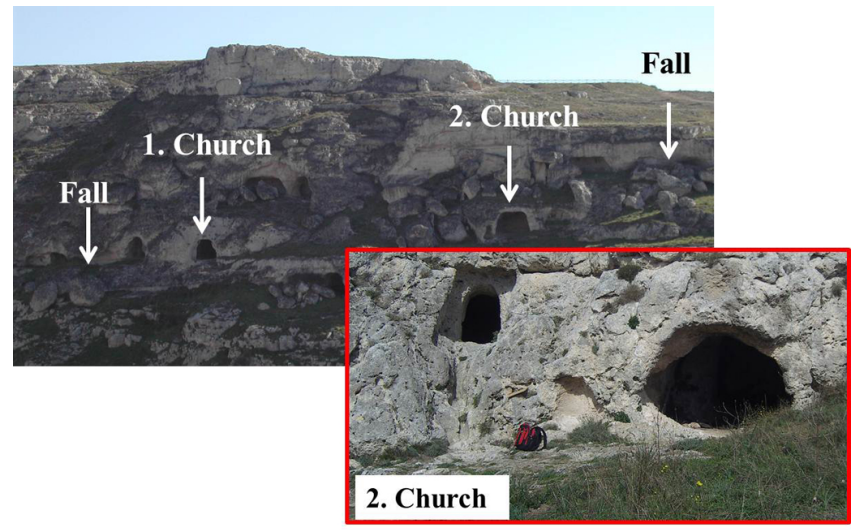

Fig. 3. "Belvedere delle Chiese Rupestri" of Matera site (Basilicata Region, southern Italy).

(Sdao et al., 2009). The GPS measurements show that the major shifts were recorded in the southern portion of the investigated site.

\subsection{Rupestrian evidences of "Parco Archeologico Storico Naturale delle Chiese Rupestri di Matera" (Southern Italy)}

The historic "Sassi of Matera" and the religious complex of the "Belvedere Chiese Rupestri" are one of the main medieval settlements of the Matera territory. They run along steep and rugged carbonate slopes that rise to about $200 \mathrm{~m}$ above the "Gravina" stream of Matera. These slopes occupy the top shelf of a platform of marine abrasions at 405$415 \mathrm{~m}$ a.s.1.

In this area, there are several archaeological sites: in addition to numerous caves dug in erodible calcarenitic soil, many of which have changed the architecture of the rocks and were intended as places of worship, where some significant churches are present (St. Vito, St. Agnese and "Madonna delle Tre Porte" churchs). These crypts are characterized by a different state of conservation, with a rather simple architecture. Well made cave paintings, often degraded, are visible (Fig. 3).

This habitat was perfect for the socio-economical, religious and strategic needs of the medieval Lucanian population (Fonseca, 1970; Laureano, 1993). People used to make their houses by excavating the friable Calcarenite of Gravina (the main lithological type outcropping at the top of Matera's Gravina) or by using its natural holes. These important archaeological sites are often affected by static instability due to the relative mass movements (Fig. 2).

\section{Neuro-fuzzy model}

\subsection{Neuro-fuzzy networks}

Neural networks and fuzzy logic can be inserted into the large category of soft computing methods. They solve problems of their domain by using approximating functions. A neuro-fuzzy model represents the integration of neural networks and fuzzy logic and fills the lacunae of both fuzzy systems and neural networks. Fuzzy neural networks do not acquire knowledge from the input-output relationships but need heuristic rules. The advantage of a neuro-fuzzy network compared with a neural network concerns the structure that can be represented by linguistic rules. The nodes of the neuro-fuzzy network do not have weights, as in a system based on neural network. The network training occurs with a back-propagation algorithm. Adaptive neuro-fuzzy inference models, ANFIS (Zimmermann, 1991), acquire knowledge of data by using typical operational algorithms of neural networks. The neuro-fuzzy models, in contrast to fuzzy models, use training data to acquire knowledge of the data to be analyzed (Saad and Halgamuge, 2004). Thus, neuro-fuzzy algorithms allow us to calibrate the membership functions of fuzzy inference with the training of an artificial neural network. Essentially, they are neural networks structured on five different levels (Fig. 4). A fuzzy model differs from a neurofuzzy model for training capacity able to automatically generate the fuzzy rules. The learning process is deemed efficient when the network solves the problem and when the error is below a certain threshold.

Generally, a neuro-fuzzy network model is characterized by a five-level network. The nodes of the first layer incorporate the membership functions associated with the fuzzy term. The nodes of the second level, however, incorporate the antecedents of the fuzzy rules. Within these nodes the "AND" logical operation is performed between active inputs.

In the third level, moreover, each node calculates the degree of satisfaction of each rule and returns a weighted term which enters as input in the corresponding node of the next level. The nodes of the fourth layer incorporate the consequent rules. Each node accepts, in input, the first level variables and the corresponding weight that comes from the previous level. Finally, the fifth nodes perform the sum of all inputs and returns the final output of the system.

The neuro-fuzzy network is also a fuzzy based approach. The definition of membership function and "if-then-else" rules are the basis of the network. A membership function associates a value (usually numeric) to the degree of membership. The real number that represents the membership degree $[\mu(x)]$ assumes value 0 when the element does not belong to the set, and value 1 when it entirely belongs to the set. The membership functions should be defined in order to be able to realistically describe the phenomenon to be modelled. In the membership function definition it is necessary to satisfactorily represent the phenomenon trend and to identify the 


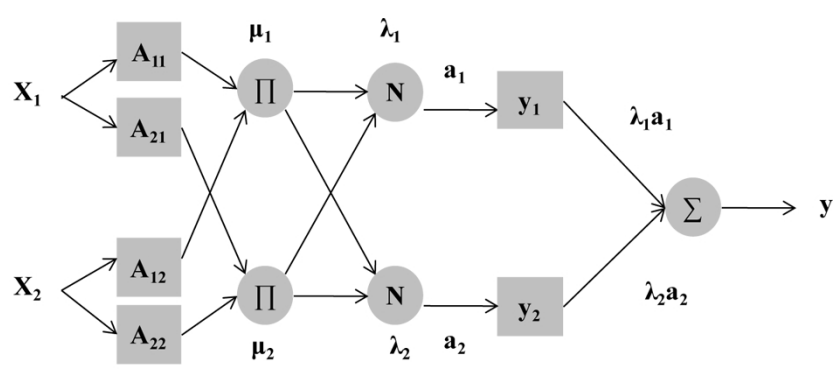

Fig. 4. Architecture of a neuro-fuzzy network.

values of the parameters and the degree of freedom of each curve.

The fuzzy rules are a way to relate a description of a phenomenon in linguistic terms with an action to be performed, expressed in linguistic terms. They are a representations of logical inferences made on compositions of fuzzy propositions. The rules are composed of an antecedent and a consequent, which can be constituted by any combination of fuzzy propositions. However, in most applications, they are in conjunction with each other. Thus the rules are represented in this form:

if ( $X$ is $L X)$ and ( $Y$ is $L Y)$ and ... and ( $Z$ is $L Z)$ then ( $U$ is $L U)$,

where $X, Y, Z$ are variables called linguistic, $L X, L Y, L Z$ are names of fuzzy sets for that variables and $U$ is the fuzzy output and $L U$ is the fuzzy set of the output.

\subsection{Neuro-fuzzy model for the landslide susceptibility evaluation}

\subsubsection{Landslide inventory map and definition of the predisposing factors}

In order, to develop a method for the assessment of the landslide susceptibility, the definition of the predisposing factors for the landslides is crucial.

The calculations of the stability conditions of a slope and thus of its level of susceptibility require the acquisition of qualitative and quantitative parameters: geological, hydrogeological, geomorphological and mechanical properties of the lithotypes. Input parameters, which are used to evaluate susceptibility, represent the causes or factors affecting the distribution of landslides in the area under study (Soeters and Van Westen, 1996; Ermini et al., 2005; Catani et al., 2005; Ercanoglu, 2005, 2011). The parameters utilized in the analysis are variables which have an influence on the landslide hazard and can be nominal or numeric (Caniani et al., 2008; Catani et al., 2005; Ercanoglu, 2005). In this study, we chose to represent each variable with a sequence of binary numbers, in order to avoid the introduction of diverse types of variables. For this reason, both nominal and numeric variables were subdivided into appropriate classes, defined on the basis of the influence that they exert on landslide mechanisms, and expressed in the interval $[0 ; 1]$.

The methodology applied in this study is based on the well-known principle of "today and past are keys to the future" (Ercanoglu and Gokceoglu, 2004), which is the fundamental principle of landslide susceptibility mapping studies. The characteristics of the existing landslides are indispensable to evaluate the possible areas of future landslides. A detailed landslide inventory map of the study area (Fig. 1) was realized in a 1:8000 scale with the interpretation of aerial photographs acquired in 2010 and with extensive field studies carried out in 2012. In the study area, a total of 113 landslides were identified. According to the classification of Varnes (1978), the dominant types of failure are: rotational slide, translational slide (Fig. 2), rock fall, toppling, planar and wedge failure. The properties of the landslides are recorded on a standard landslide inventory data sheet but the main purpose of this study was the mapping of the boundaries of the landslides. The areas between the crest and the zone of depletion of the landslides are mapped. All the used landslide features were obtained from digital parameter maps, as we discuss in the following paragraphs.

Several authors (Catani et al., 2005; Ermini et al., 2005; Ercanoglu, 2005, 2011; Pereira et al., 2012) studied various input parameters. In this study, nine factors were selected (Fig. 5): lithology, elevation, plane curvature, angle and aspect of the slope, fracture density, kinematic hazard index of planar and wedge sliding and toppling. Contours and survey base points, which have an elevation value, were extracted from the topographic map. A digital elevation model (DEM) was constructed by using the inverse distance weighting (IDW) method of interpolation with $3 \times 3 \mathrm{~m}$ resolution. Slope angle, slope aspect, and plan curvature were extracted from DEM.

The accuracy of DEM was quantitatively verified on the basis of several field-surveyed points, by using GPS and total station points.

The Kinematic hazard index (Casagli and Pini, 1993) uses kinematic criteria and allows us the estimation of a dimensionless index (kinematic hazard ratio) for each possible mechanism of the movement of blocks. The kinematic hazard ratio index is expressed by the ratio of the number of poles or intersections that satisfy the kinematic conditions of instability and the total number of poles acquired. These indices are defined as follows:

$C_{\mathrm{SP}}=\frac{N_{\mathrm{SP}}}{N}(\%)$,

where $C_{\mathrm{SP}}$ is the kinematic danger index for the planar sliding, $N_{\mathrm{SP}}$ is the number of poles which satisfy the kinematic conditions of instability and $N$ is the total number of poles;

$C_{\mathrm{SC}}=\frac{N_{\mathrm{SC}}}{N}(\%)$,

where $C_{\mathrm{SC}}$ is the index of kinematic hazard for the wedge sliding, $N_{\mathrm{SC}}$ is the number of intersections which satisfy the 


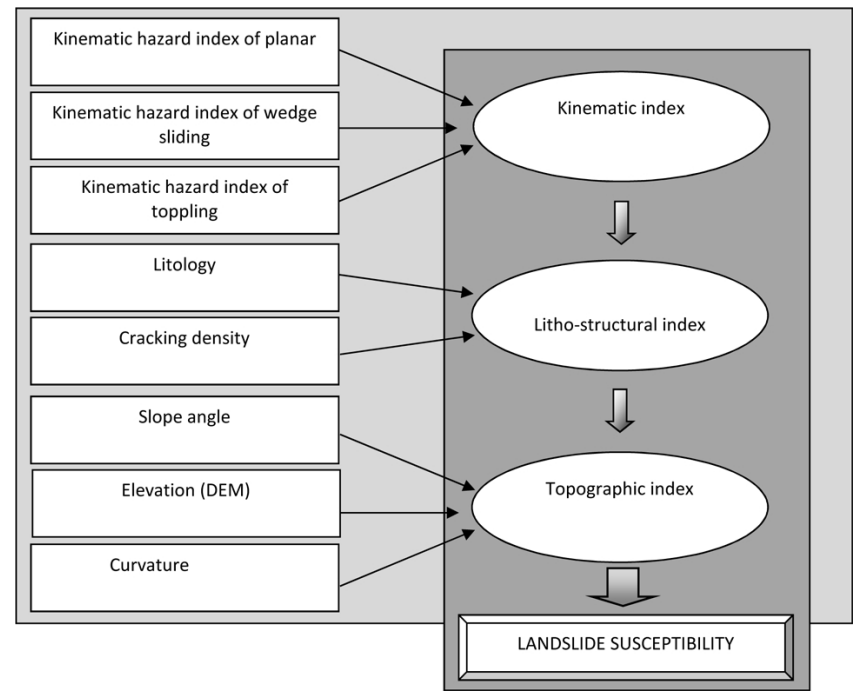

Fig. 5. Flow chart of the developed neuro-fuzzy model for the landslide susceptibility assessment.

kinematic conditions of instability, while $N$ is the total number of intersections between the identified discontinuities;

$C_{\mathrm{RD}}=\frac{N_{\mathrm{RD}}}{N} \times \frac{I_{\mathrm{RD}}}{I}(\%)$,

where $C_{\mathrm{RD}}$ is the kinematic danger index for direct tipping, $N_{\mathrm{RD}}$ is the number of poles which satisfy the kinematic conditions of instability, $N$ is the total number of poles. RD is the number of intersections which satisfy the kinematic conditions of instability, while $I$ is the total number of intersections.

These indices, whether the sample spatial arrangement data is significantly large, provide, on the basis of the kinematic boundary conditions, an estimation of the relative probability, and therefore of the relative hazard that a given movement mechanism occurs at a given point of the slope.

The size of pixels of the landslide inventory map and all the maps of parameter was chosen as $3 \times 3 \mathrm{~m}$ (136 columns and 302 rows, i.e. 41072 pixels) and the working scale was selected as $1: 500$.

\subsubsection{Methodology for the landslide susceptibility assessment}

The prediction model for the landslide susceptibility evaluation of the Natural Archaeological Park of Matera (Southern Italy) is based on an Adaptive Neural Network-based Fuzzy Inference System (ANFIS). This model allows us to train the network starting with a training matrix. We have classified the input parameters in the neuro-fuzzy model as kinematic, topographic and litho-structural parameters. The neuro-fuzzy model for the susceptibility assessment is characterized by sub-groups in order to reduce the computational burden. We have determined the three indices by applying fuzzy logic in

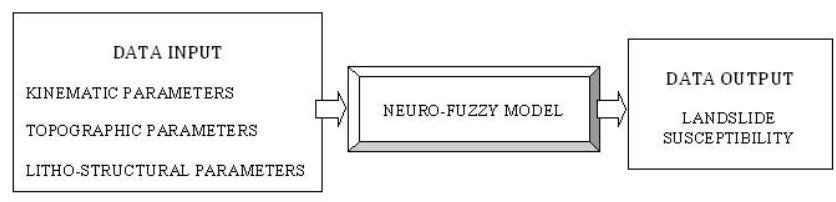

Fig. 6. Flow chart of the input and output data of the neuro-fuzzy model for the evaluation of landslide susceptibility.

each subgroup (Figs. 5 and 6): kinematic index, topographic index and litho-structural index (Fig. 7). These three indices represent the input data to the neuro-fuzzy model. The kinematic index identifies the potential of ignition of landslides and contains kinematic hazard index of planar and wedge sliding and toppling. The topographic index is related to the slopes morphology and is characterized by slope angle, elevation and plan curvature. The litho-structural index, however, considers the lithology and the fracture density (Candan et al., 2004). The network training was performed through a matrix consisting of input parameters and a single output value, i.e. the landslide susceptibility index. The input indexes were determined by fuzzy approach (kinematic index, litho-structural index and topographic index). At this point of the analysis, in the neuro-fuzzy model the membership functions were defined. We overcame the subjective selection of the membership functions (Fig. 8) by combining the neurofuzzy model with a sensitivity analysis, which was used as a decision tool for the selection of the most appropriate membership functions. It consists in running several simulations in which from time to time these functions are changed. The results obtained from the simulations were subjected to a statistical analysis which allowed us to perform a validation between simulation output data and real information taken from the landslide inventory map (Oh et al., 2011). The sensitivity analysis (Caniani et al., 2010) revealed itself to be a valid solution to reduce the subjectivity.

The model for the landslide susceptibility evaluation was implemented in Matlab (MathWorks). The Matlab code allows us: to draw the training matrix, to define the membership functions and their respective classes, and to assign the epochs number, i.e. the iteration number. The Matlab ANFIS function consists of four phases:

- initialization, which is defined by the function "genfis1", where the membership functions are defined;

- training, which is used to train the network and is identified by the ANFIS function;

- testing, which allows us to evaluate the error of training;

- the "evalfis" function, which determines the values of the environmental risk related to site data.

The parameters were implemented in raster format and they were converted into text files for processing. The 


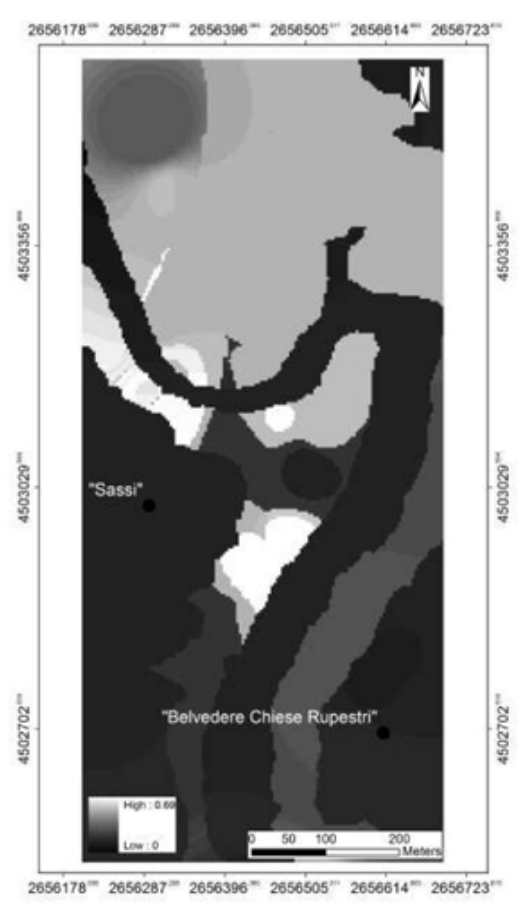

Kinematic index map

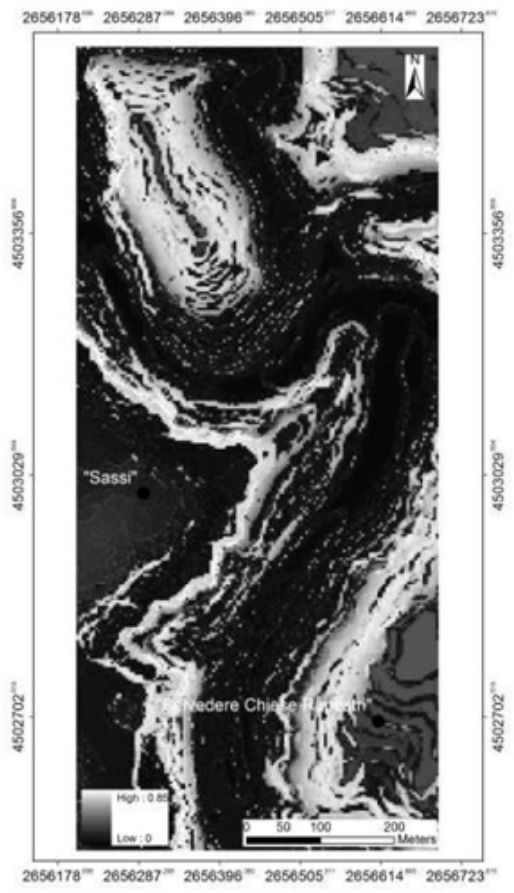

Topographic index map

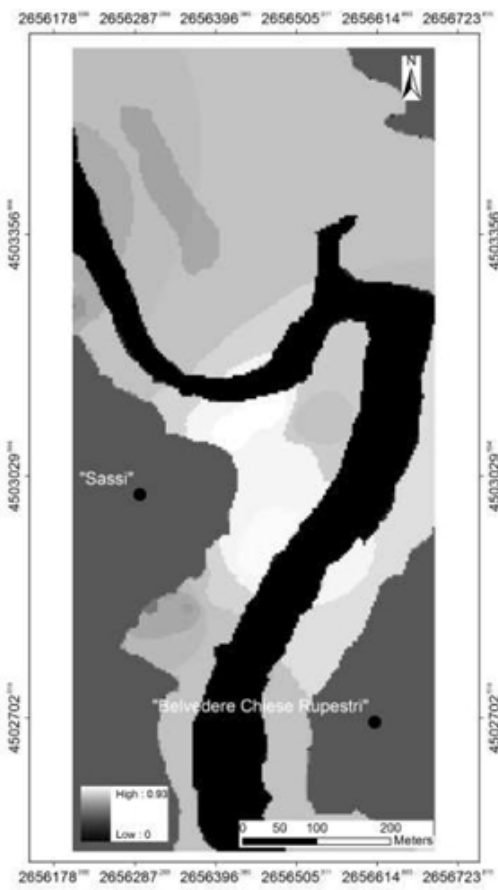

Litho-structural index map

Fig. 7. Input data to the neuro-fuzzy model for the landslide susceptibility assessment: (a) kinematic index map, (b) topographic index map and (c) litho-structural index map.

neuro-fuzzy model was constructed by assigning a training matrix, a epoch number equal to 100 and the type of membership functions in the various schemes. The training matrix was used to train the network and was created by combining all the parameters characterizing the landslide susceptibility. The matrix is characterized by the input parameters and one output, the landslide susceptibility, which varies from zero to one.

\subsubsection{Methodology for the model validation}

The application of the neuro-fuzzy model is divided into two steps: the training phase, in which a random selection of landslide sites was carried out and the weights were calculated, and the validation procedure, in which the obtained susceptibility map was verified with the inventory map. The validation of the landslide susceptibility analysis was carried out by using landslide sites which were not used during the first modelling phase.

The validation phase of the model has two primary objectives:

- to decide whether the model is sufficiently accurate for the landslide susceptibility evaluation, by comparing the results with the landslide inventory map;

- to determine a neuro-fuzzy scheme which is the most able to represent the slope instability.
The landslide susceptibility analysis was performed using various fuzzy operators, and the analysis results were validated using statistical methods: "Receiver operating characteristics" (ROC) method, confusion matrix (Hanley and McNeil, 1983; Zweig and Campbell, 1993; Beguerìa, 2006; Fawcett, 2006) and SCAI (Seed Cell Area Indexes) (Suzen and Doyuran, 2004) method. ROC method is a methodology created during World War II to analyze radar images and to study the signal/noise ratio. ROC analysis is an extremely versatile statistical method, used in various fields of science, including medicine (Lusted, 1971). ROC analysis (Bottarelli and Parodi, 2003) links the probability of getting a true-positive result for landslide sites to the probability of obtaining a false positive result in the class of sites which are not in landslides (Fawcett, 2006; Conforti et al., 2012; Lucà et al., 2011). The analysis was conducted comparing the results of the landslide susceptibility derived from eight neuro-fuzzy schemes and the landslide inventory map. The ROC analysis was carried out by overlapping the landslide susceptibility obtained with the neuro-fuzzy network and the landslide inventory map (Pereira et al., 2012). It visualizes a classifier performance in order to select the proper decision threshold and provides a probability of detection versus a probability of false alarm curve (Fawcett, 2006). The ROC curves are equivalent to prediction and success-rate curves proposed by Chung and Fabbri (2003). The area under the 


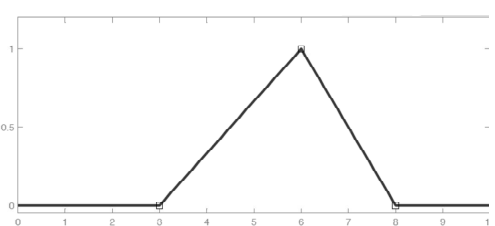

a)

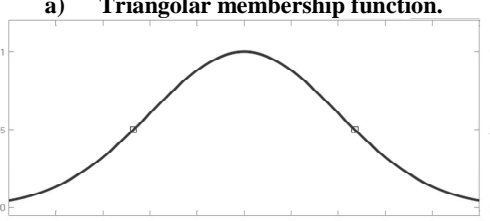

c) Gauss membership function.

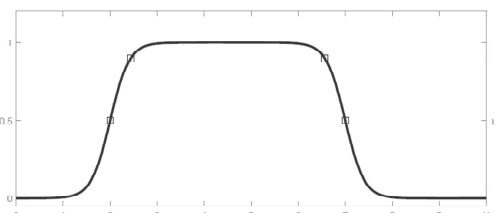

f) Dsig membership function.

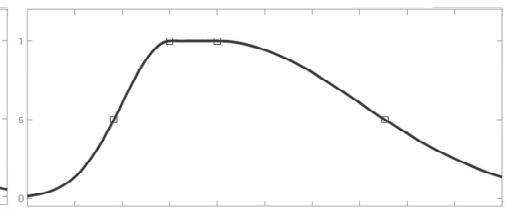

d) Gauss 2 membership function.

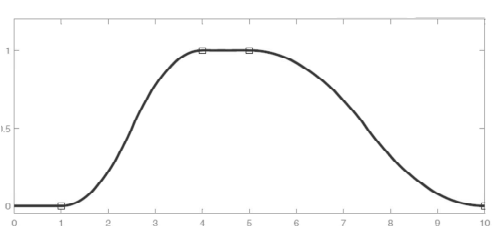

g) Pi membership function.

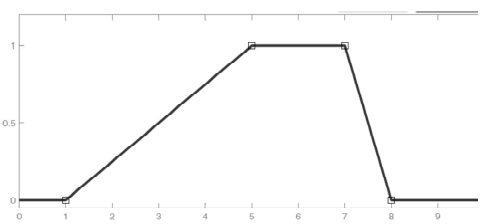

b) Trapezoidal membership function.

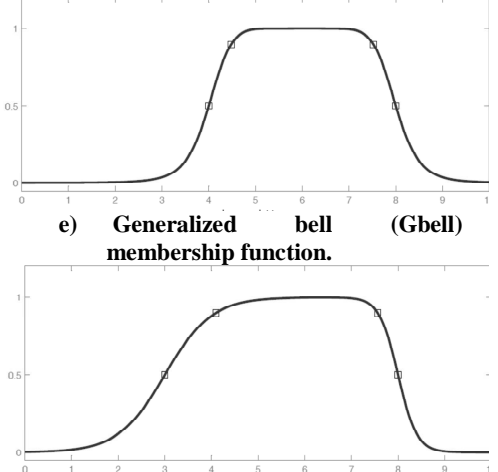

h) Psig membership function.

Fig. 8. Membership functions of neuro-fuzzy model.

ROC curve (AUC) represents a fundamental parameter for the evaluation of the test performance (Swets, 1998). It is a measure of the accuracy which is independent on the prevalence (pure accuracy). The area is a measure of discrimination, i.e. the ability of the technique to classify the pixels correctly. This threshold-independent measure of discrimination between both classes takes values between 0.5 (no discrimination) and 1 (perfect discrimination). Therefore, the closer the ROC plot is to the upper left corner, the higher the overall accuracy of the test is. An area of 1 represents a perfect test and an area of 0.5 represents a worthless test. This procedure allows us to verify if the proportion of true positives is superior to that of false positives. A rough guide for knowing the accuracy of a classifier is $0.5-0.6$ for a fail, $0.6-0.7$ for poor, $0.7-0.8$ for fair, $0.8-0.9$ for good, and $0.9-1$ for excellent.

A confusion matrix, other statistical method to validation model, provides the accuracy of the obtained classification. The confusion matrix was calculated by comparing the location and class of each ground truth pixel with the corresponding location and class in the obtained classified image. The overall accuracy was calculated by summing the number of pixels classified correctly and dividing it by the total number of pixels.

Finally, to further assess the consistency of the model, the seed cell area index (SCAI) of Suzen and Doyuran (2004) was computed as follows:

$\mathrm{SCAI}=$

Areal extent of susceptibility classes (\%)

$\overline{\mathrm{LDZ}}$ of the training and testing set in each susceptibility class (\%).
The logic behind SCAI lies in the correct classification of landslide pixels within a very conservative areal extent, and it is expected that the high and very high susceptibility classes should have very small SCAI values, and that low and very low susceptibility classes should have higher SCAI values (Kincal et al., 2009). In this context, the susceptibility area percent values are divided by the landslide pixels percent values. The resulting values are the SCAI densities of landslide pixels among the landslide susceptibility classes.

\section{Results of the landslide susceptibility mapping by using the neuro-fuzzy model}

The neuro-fuzzy model was applied to the portion of the area of the Matera Municipality (Basilicata Region, Southern Italy) where the landslide inventory map is available. The landslide susceptibility was assessed by examining various environmental factors by using fuzzy membership functions, as described in Sect. 3.2. The conditioning parameters responsible for the instability of the slopes and the fuzzy membership functions were determined. In order to validate the results of the methodology for the assessment of the landslide susceptibility, a landslide inventory map was created for the study area, which comprised 113 landslides. The landslides were located by using aerial photographs; field checks confirmed the accuracy of these locations.

Landslide pixels and an equal number of non-landslide pixels were randomly selected for the generation of the landslide susceptibility map $(50 \%)$ and for validation purposes $(50 \%)$. The results obtained from the simulations identify a 


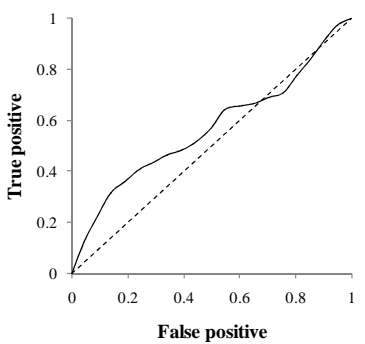

a) ROC curve by using Trapezoidal membership function in neuro-fuzzy model $(\mathrm{AUC}=\mathbf{0 . 5 7})$

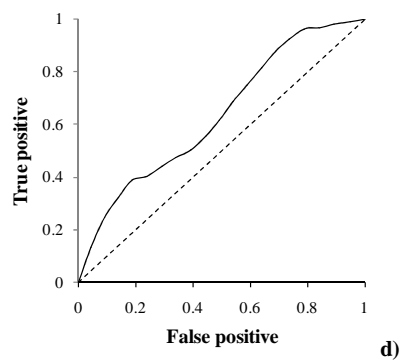

ROC curve by using Gauss 2 membership function in neuro-fuzzy model (AUC=0.64)

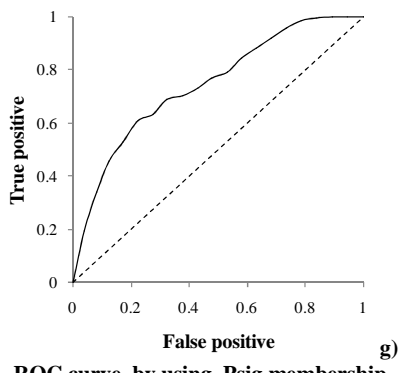

ROC curve by using Psig membership function in neuro-fuzzy model (AUC=0.75)

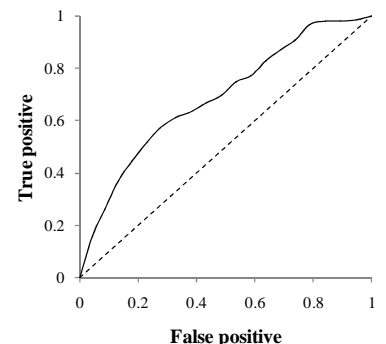

b) ROC curve by using Triangular membership function in neuro-fuzzy model $(\mathrm{AUC}=\mathbf{0 . 5 9})$

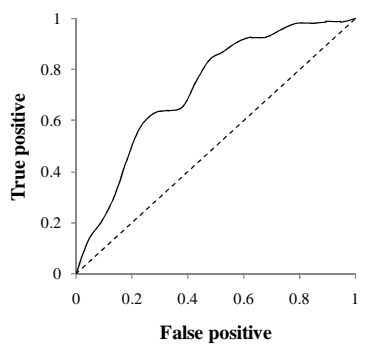

e) ROC curve by using Gbell membership function in neuro-fuzzy model $(\mathrm{AUC}=\mathbf{0 . 7 3})$

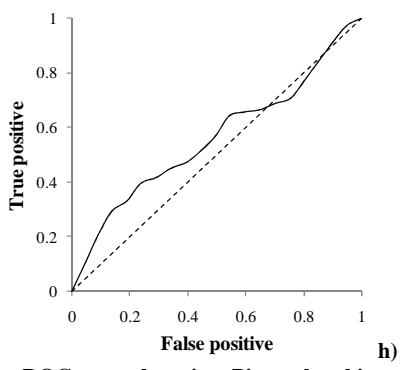

ROC curve by using Pi membership function in neuro-fuzzy model (AUC $=0.56)$

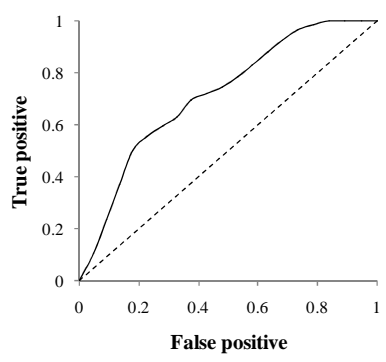

c) ROC curve by using Gauss membership function in neuro-fuzzy model $(A U C=0.72)$

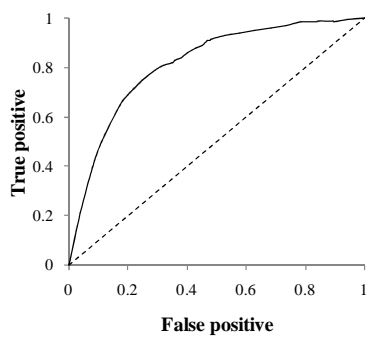

f) ROC curve by using Dsig membership function in neuro-fuzzy model (AUC $=0.85$ )

Fig. 9. Model validation with ROC curves.

landslide susceptibility map with an index variable between 0 and 1 . This index has been obtained from topographic, lithostructural and kinematic indexes (Figs. 5, 6 and 7). These indexes were obtained by performing an initial fuzzy analysis on the descriptor parameters of the instability of the area (Figs. 5 and 7). Subsequently these indexes were used in the neuro-fuzzy model in order to calculate the landslide susceptibility of the Natural Archaeological Park of Matera, as described in Fig. 6. The output of the Matlab neuro-fuzzy model have been subsequently spatially represented in a GIS software. The maps are represented with the same number of classes, for a congruous comparison of data.

The results emerging from the neuro-fuzzy model are expressed by a landslide susceptibility index variable between 0 and 1 . This index has been later reclassified by using the Natural Break method (Jenks, 1977) (Fig. 10) in order to obtain the susceptibility map of the study area (Fig. 11), which classifies the stability of the study area into five susceptibility classes that range from stable to unstable.

The susceptibility classes are no susceptibility, low, medium, high, and very high susceptibility (Fig. 12). According to this map, $5.3 \%$ of the study area is classified as very high susceptible, $6.9 \%$ as high susceptible, $28.7 \%$ as medium susceptible, $29.0 \%$ as low susceptible and $30.1 \%$ as no susceptible areas.

High and very high susceptibilities, which cover about $15.4 \%$ of the study area, represent the south-western portions of the study area. This result is in accordance with the concentration on this area of more than $61 \%$ of the landslide mapped. In addition, the calcarenitic rocks, which are intensively fractured and are characterized by steep slopes (more than $30^{\circ}$ in average), were found to be the more prone to instability. On the contrary, low and very low landslide susceptibilities, which cover about $59.1 \%$ of the study area, 


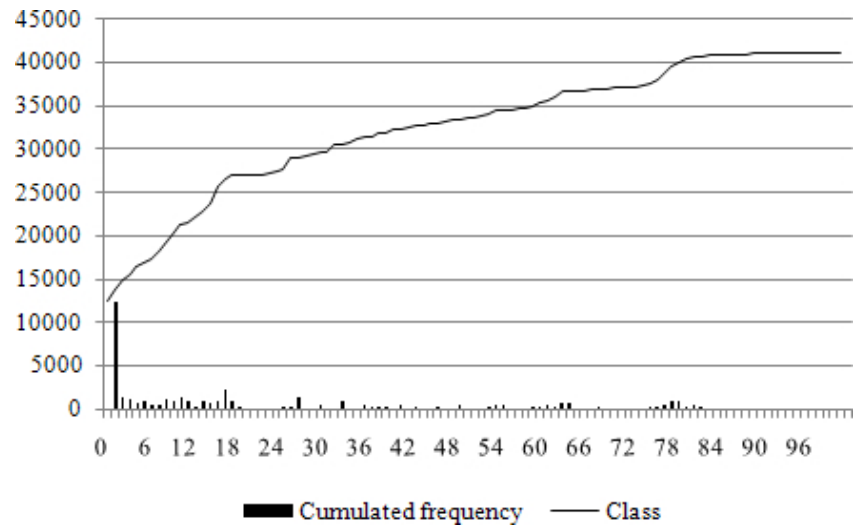

Fig. 10. Class subdivision of the susceptibility map with the Natural Breaks method.

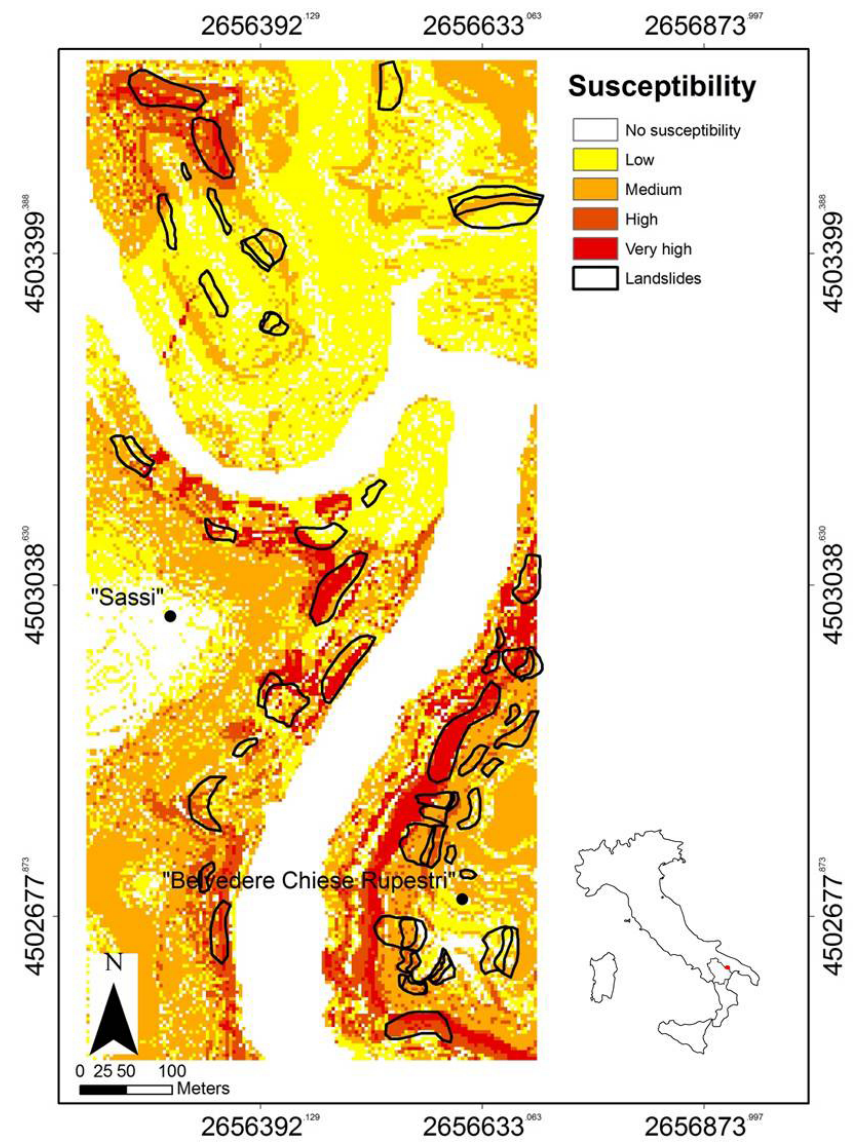

Fig. 11. Overlay of the susceptibility map (with Dsig membership function) and the landslide inventory map.

occur where slope ranges between $0^{\circ}$ and $10^{\circ}$ (flat or gently sloping land surfaces). The comparison between the susceptibility map and the landslides inventory map (Fig. 11) shows that more than of $86 \%$ of the overall landslides data set were correctly classified (Table 1).

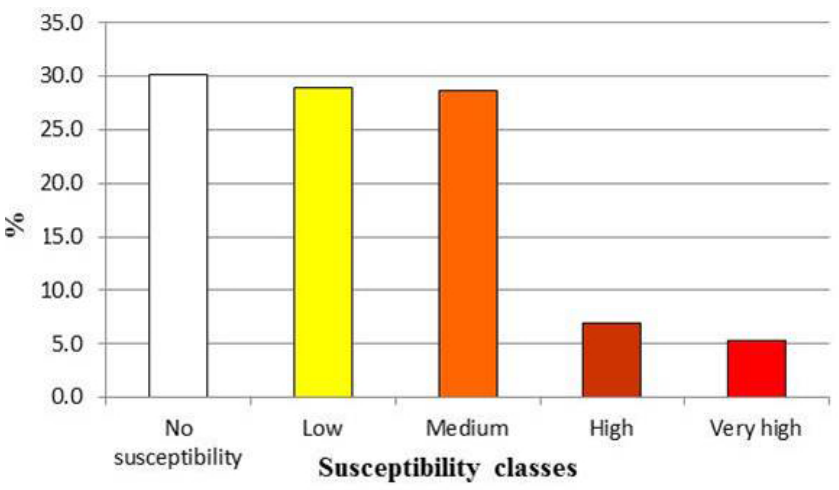

Fig. 12. Pixel percentage of susceptibility map classified into five levels: no susceptibility, low, medium, high, and very high.

\section{Validation and accuracy analysis of the neuro-fuzzy model}

Results obtained from the statistical analysis are shown in Fig. $9 a, \ldots, h$.

The ROC method allowed us to identify the most valid neuro-fuzzy model and the one which returns results similar to reality (landslide inventory map). The best model gave the value of AUC $>0.8$.

The ROC curve analysis identified that the best result is obtained from the neuro-fuzzy model in which we considered the Gauss (Fig. 9c) and the Dsig (Fig. 9f) membership functions. This is demonstrated by the performance of the ROC curve and by the area subtended to curves. The most accurate result $(\mathrm{AUC}=0.85)$ is obtained by applying the model which is characterized by the Dsig membership function.

The validation of the susceptibility map obtained with the Dsig membership function was also performed using a confusion matrix. The results of the neuro-fuzzy model have an overall accuracy of $87 \%$. The observed and predicted accuracy are shown in Table 1 . The predicted accuracy is a measure indicating the probability that the classifier has labelled an image pixel into Class A when the ground truth is Class A. The results reported in Table 1 show that predicted accuracy is $79 \%$ for landslide cells and $95 \%$ for non-landslide cells. The overall predicted accuracy is $87 \%$.

Finally, to further assess the consistency of the model, the landslide susceptibility analyses obtained by Dsig membership function were also validated using the SCAI method proposed by Suzen and Doyuran (2004). In this context, the percentages of susceptibility are divided by the percentages of landslide cells in order to develop the SCAI density of landslides for the classes (Table 2). The SCAI values show that the generated maps are generally accurate because the high and very high susceptibility classes have very low SCAI values, whereas the SCAI values of the very low and low susceptibility classes are very high. 
Table 1. Confusion matrix of the testing data set (cut-off value: 0.5 ).

\begin{tabular}{lccr}
\hline & \multicolumn{2}{c}{ Observed predicted } & \multirow{2}{*}{$\%$ correct } \\
\cline { 2 - 3 } & $\begin{array}{c}\text { Landslide } \\
\text { cells }\end{array}$ & $\begin{array}{c}\text { Non-occurrence } \\
\text { landslide cells }\end{array}$ & \\
\hline Landslide cells & 1078 & 287 & 79 \\
Non-occurrence landslide cells & 67 & 1271 & 95 \\
Overall accuracy & & & 87 \\
\hline
\end{tabular}

Table 2. Area percentage of the susceptibility classes in the map. Landslide cells training set and landslide cells testing set falling in each susceptibility class and SCAI values.

\begin{tabular}{llrrrrr}
\hline $\begin{array}{l}\text { Susceptibility } \\
\text { values }\end{array}$ & $\begin{array}{l}\text { Susceptibility } \\
\text { class }\end{array}$ & $\begin{array}{r}\text { Area } \\
(\%)\end{array}$ & $\begin{array}{r}\text { Landslide cells } \\
\text { training set }(\%)\end{array}$ & $\begin{array}{r}\text { \% Landslide cells } \\
\text { testing set (\%) }\end{array}$ & $\begin{array}{r}\text { All landslide } \\
\text { cells (\%) }\end{array}$ & SCAI \\
\hline $0-0.0085$ & Very low & 30.1 & 8.4 & 4.2 & 6.4 & 4.7 \\
$0.0085-0.13$ & Low & 29.3 & 31.5 & 13.6 & 23.5 & 1.24 \\
$0.13-0.53$ & Moderate & 28.4 & 39.4 & 17.8 & 29.5 & 0.96 \\
$0.53-0.66$ & High & 6.9 & 10.6 & 27.4 & 18.3 & 0.38 \\
$0.66-1$ & Very high & 5.3 & 10.1 & 37.0 & 22.4 & 0.24 \\
\hline
\end{tabular}

\section{Conclusions}

The landslide susceptibility assessment is a recurring important topic in the geological and geomorphological fields; the main aim of the proposed procedure is to act as a support in planning decisions. The literature proposes different qualitative and quantitative methods. The choice of the method to be applied depends on the degree of precision and detail that we need to obtain from the model. In some cases, the artificial intelligence techniques allow us to overcome the problems related to the high number of parameters and their uncertainty. The assessment of the susceptibility of the area under study was achieved by adopting a mixed model based on the application of statistical methods integrated into computational neuro-fuzzy systems (ANFIS), in order to reduce the degree of subjectivity. It is fast and economical and it is applicable to different problems including the study of territory landslides. The present study applied this technique in a Rupestrian Heritage Rich Area of Matera.

A landslide database of the study area was compiled by field and air photo studies. In the study area, a total of 113 landslides were identified. The dominant mode of failure is rotational slide, rock fall, toppling, planar and wedge failure. The landslide predisposing factors considered were lithology, elevation, plane curvature, angle and aspect of the slope, fracture density, kinematic hazard index of planar and wedge sliding and toppling. The validation process was performed with a confusion matrix, the ROC analysis and the SCAI method. The ROC analysis was a valid tool to identify the best result emerging from the simulations characterized by different fuzzy membership functions. The ROC analysis provides the AUC values that express the model ac- curacy, by comparing the landslide inventory map and the landslide susceptibility map obtained from the neuro-fuzzy model. The Dsig membership function was identified as the function which gives the optimal landslide susceptibility map obtained with the neuro-fuzzy model (AUC $=0.85$ ).

The validation procedure, which was carried out on a testing data set, confirmed the effectiveness (AUC of the ROC curve: 0.90) of the developed model to predict landslide. Also, the result of validation shows an overall accuracy of the $87 \%$ with the $91 \%$ of all landslide cells testing set correctly classified. These results suggest a good performance of the used method. The validation procedure, which was performed by using another testing data set, confirmed the effectiveness of the model to predict landslides; in fact, the confusion matrix shows an overall accuracy of $87 \%$ with the $79 \%$ of the landslide testing set correctly classified. The predictive power was further confirmed by the very low SCAI values in the highest susceptibility classes.

We conclude, after the previous considerations, that the developed neuro-fuzzy system can be a relatively simple answer to the resolution of complex problems such as those regarding the assessment of landslide susceptibility. Moreover, the developed neuro-fuzzy model showed to be an objective methodology thanks to its integration with sensitivity analysis.

Acknowledgements. We thank Serena Parisi for critical reading of the paper.

Edited by: R. Lasaponara

Reviewed by: B. Haneberg and two anonymous referees 


\section{References}

Attia, A. F., Abdel-Hamid, R., and Quassim, M.: Prediction of solar activity based on neuro-fuzzy modelling, Solar Phys., 227, 177191, 2005.

Beguería, S.: Validation and evaluation of predictive models in hazard assessment and risk management, Nat. Hazards, 37, 315329, 2006.

Bottarelli, E. and Parodi, S.: Un approccio per la valutazione della validità dei test diagnostici: le curve R.O.C. (Receiver Operating Characteristic, Ann. Fac. Medic. Vet. di Parma (Vol. XXIII, 2003), 49-68, 2003.

Candan, G., Ertan, Y., Harun, S., and Kayabasi, A.: A neuro-fuzzy model for modulus of deformation of jointed rock masses, Comput. Geotech., 31, 375-383, 2004.

Caniani, D., Pascale, S., Sdao, F., and Sole, A.: Neural networks and landslide susceptibility: a case study of the urban area of Potenza, Nat. Hazards, 45, 55-72, 2008.

Caniani, D., Lioi, D. S., Mancini, I. M., and Masi, S.: Application of fuzzy logic and sensitivity analysis for soil contamination hazard classification, Waste Manage., 31, 583-594, 2010.

Casagli, N. and Pini, G. A.: Analisi cinematica della stabilità di versanti naturali e fronti di scavo in roccia, Atti $3^{\circ}$ Convegno Nazionale dei Giovani Ricercatori in Geologia Applicata, Potenza, 28-30 Ottobre 1993.

Catani, F., Casagli, N., Ermini, L., Righini, G., and Menduni, G.: Landslide hazard and risk mapping at catchment scale in the Arno River basin, Landslides, 2, 329-342, 2005.

Chung, C. J. F. and Fabbri, A. G.: Validation of spatial prediction models for landslide hazard mapping, Nat. Hazards, 30, 451472, 2003

Conforti, M., Robustelli, G., Muto, F., and Critelli, S.: Application and validation of bivariate GIS-based landslide susceptibility assessment for the Vitravo river catchment (Calabria, south Italy), Nat. Hazards, 61, 127-141, 2012.

Cotecchia, V. and Grassi, D.: Incidenze geologico-ambientali sull'ubicazione e lo stato di degrado degli insediamenti rupestri medioevali della Puglia e della Basilicata, Geol. Appl. e Idrogeol., 32, 1-10, 2 tavv. f.t. Bari, 1997.

De Bari, C., Lapenna, V., Perrone, A., Puglisi, C., and Sdao, F.: Digital photogrammetric analysis and electrical resistivity tomography for investigating the Picerno landslide (Basilicata region, southern Italy), Geomorph. J., 133, 34-46, 2011.

Dixon, B.: Applicability of neuro-fuzzy techniques in predicting ground-water vulnerability: a GIS-based sensitivity analysis, J. Hydrol., 309, 17-38, 2005.

Duško, K. and Miomir, V.: Survey of Intelligent Control Techniques for Humanoid Robots, J. Int. Robotic Syst., 37, 117-141, 2003.

Ercanoglu, M.: Landslide susceptibility assessment of SE Bartin (West Black Sea region, Turkey) by artificial neural networks, Nat. Hazards Earth Syst. Sci., 5, 979-992, doi:10.5194/nhess-5979-2005, 2005.

Ercanoglu, M. and Gokceoglu, C.: Use of fuzzy relations to produce landslide susceptibility map of a landslide prone area (WestBlack Sea Region, Turkey), Eng. Geol., 75, 229-250, 2004.

Ercanoglu, M. and Temiz, F. A.: Application of logistic regression and fuzzy operators to landslide susceptibility assessment in Azdavay (Kastamonu, Turkey), Environ. Earth Sci., 64, 949-964, 2011.
Ermini, L., Catani, F., and Casagli, N.: Artificial neural networks applied to landslide susceptibility assessment, Geomorphology, 66, 327-343, 2005.

Fawcett, T.: An introduction to ROC analysis, Pattern Recog. Lett., 27, 861-874, 2006.

Fonseca, C. D.: Civiltà Rupestre in Terra Jonica, Ed. Bestetti, Roma, 1970.

Gemitzi, A., Falalakis, G., Eskioglou, P., and Petalas, C.: Evaluating landslide susceptibility using environmental factors fuzzy membership functions and gis global, Nest J., 12, 1-13, 2010.

Gullà, G. and Sdao, F.: Dissesti prodotti o aggravati dal sisma del 9 settembre 1998 nei territori del Confine calabro-lucano, Monografia del Gruppo Nazionale Difesa Catastrofi Idrogeologiche, CNR - 112 pp., Rubbettino Ed. srl, Soveria Mannelli (CZ), Pubbl. n. 2121 del catalogo pubblicazioni del GNDCI, CNR., 2001.

Hanley, J. A. and McNeil, B. J.: A method of comparing the areas under receiver operating characteristic curves derived from the same cases, Radiology, 148, 839-843, 1983.

Henry, J. J., Farges, J. L., and Gallego, J. L.: Neuro-fuzzy techniques for traffic control, Control Eng. Practice, 6, 755-761, 1998.

Hudson, J. A. and Harrison, J. P.: Engineering rock mechanics, An introduction to the principles, Pergamon press, 1993.

Iyatomi, H. and Hagiwara, M.: Adaptive fuzzy inference neural network, Pattern Recog., 37, 2049-2057, 2004.

Jenks, G. F.: Optimal data classification for choropleth maps, Occasional paper No. 2, Lawrence, Kansas:University of Kansas, Department of Geography, 1977.

Kıncal, C., Akgun, A., and Koca, M. Y.: Landslide susceptibility assessment in the Izmir (West Anatolia, Turkey) city center and its near vicinity by the logistic regression method, Environ. Earth Sci., 59, 745-756, 2009.

Kholghi, M. and Hosseini, S. M.: Comparison of groundwater level estimation using neuro-fuzzy and ordinary kriging, Environ. Model Assess., 14, 729-737, 2009.

Kurtulus, B. and Razack, M.: Modelling daily discharge responses of a large karstic aquifer using soft computing methods: Artificial neural network and neuro-fuzzy, J. Hydrol., 381, 101-111, 2010.

Laureano, P.: Giardini di pietra, I Sassi di Matera e la civiltà mediterranea, Collana Nuova Cultura, BollatiBoringhieri ed. Torino, 40, 199 pp., 1993.

Lucà, F., Conforti, M., and Robustelli, G.: Comparison of GIS based gullying susceptibility mapping using bivariate and multivariate statistics in Northern Calabria (South Italy), Geomorphology, 134, 297-308, 2011.

Lusted, L. B.: Signal detectability and medical decision-making, Science, 171, 1217-1219, 1971.

Masi, S., Mancini, I. M., Caniani, D., and Lioi, D. S.: Fuzzy logic and neuro-fuzzy networks for environmental risk assessment, Open Access book "Fuzzy Logic", ISBN 979-953-307-578-4, 2012.

Matheson, G. D.: Rock stability assessment in preliminary site investigation - Graphical Methods, Transport and road Research laboratory Report 1039, 1983.

Matheson, G. D.: The collection and the use of field discontinuity data in rock slope design, Q. J. Eng. Geol., 22, 19-30, 1989.

Muller, S., Garda, P., Muller, J.-D., René, C., and Yves, C.: A Neuro-fuzzy Coding for Processing Incomplete Data: Applica- 
tion to the Classification of Seismic Events, Neural Process. Lett., 8, 83-91, 1998.

Oh, H.-J. and Pradhan, B.: Application of a neuro-fuzzy model to landslide-susceptibility mapping for shallow landslides in a tropical hilly area, Comput. Geosci., 37, 1264-1276, 2011.

Pascale, S., Sdao, F., and Sole, A.: A model for assessing the systemic vulnerability in landslide prone areas, Nat. Hazards Earth Syst. Sci., 10, 1575-1590, doi:10.5194/nhess-10-15752010, 2010.

Pascale, S., Pastore, V., Sdao, F., Sole, A., Roubis, D., and Lorenzo, P.: Use of remote sensing data for Landslide change detection large Montescaglioso landslide (Basilicata, Southern Italy), International Journal of Agricultural and Environmental Information Systems (IJAEIS) IGI Global Publisher, Special Issue "Analysing, modelling and visualizing spatial Environmental Data”, 2012.

Pereira, S., Zêzere, J. L., and Bateira, C.: Technical Note: Assessing predictive capacity and conditional independence of landslide predisposing factors for shallow landslide susceptibility models, Nat. Hazards Earth Syst. Sci., 12, 979-988, doi:10.5194/nhess12-979-2012, 2012.

Polemio, M. and Sdao, F.: Landslide hazard and critical rainfall in Southern Italy, in: Landslides, edited by: Senneset, K., Proceedings of 6th International Symposium on Landslides, Trondheim, Giugno 1996, Balkema, Pubbl., giugno 1996, Rotterdam (Olanda), 2, 847-852, 6 ff., 1 tab., 1996.

Polemio, M. and Sdao, F.: Heavy rain falls and extensive landslides occurred in Basilicata, Southern Italy, in: 1976, Proceedings of 8th Congress of International Association of Engineering Geology and Environment, Vancouver, Canada Settembre 1998, Balkema Ed, 1998, Rotterdam. Pubbl. n. 1842 del catalogo del G.N.D.C.I., C.N.R., 1849-1855, 5 ff., 2 tabb., 1998.

Saad, R. and Halgamuge, S. K.: Stability of hierarchical fuzzy systems generated by Neuro-Fuzzy, Softw. Comput., 8, 409-416, 2004.

Sdao, F. and Simeone, V.: Mass movements affecting Goddess Mefitis sanctuary in Rossano di Vaglio (Basilicata, southern Italy), J. Cult. Heritage, 8, 77-80, 2007.
Sdao, F., Pascale, S., and Rutigliano, P.: Instabilità dei versanti e controllo, mediante tecniche integrate di monitoraggio, delle frane presenti in due siti sacri del Parco Archeologico Storico Naturale delle Chiese Rupestri di Matera, SIRIS Studi e ricerche della Scuola di Specializzazione in Archeologia di Matera, 9 (2008), 87-100, 2009.

Soeters, R. and Van Westen, C. J.: Slope stability recognition, analysis, and zonation application of geographical information system to landslide hazard zonation, in: Landslides: investigation and mitigation. edited by: Turner, A. K. and Schuster, R. L., Sp.-Rep. 247, Transportation Research Board, National Research Council, National Academy Press, Washington, DC, 129-177, 1996.

Suzen, L. M. and Doyuran, V.: A comparison of the GIS based landslide susceptibility assessment methods: multivariate versus bivariate, Environ. Geol., 45, 665-679, 2004.

Swets, J. A.: Measuring the accuracy of diagnostic systems, Science, 240, 1285-1293, 1998.

Tutmez, B., Hatipoglu Z. and Kaymak U.: Modelling electrical conductivity of groundwater using an adaptive neuro-fuzzy inference system, Comput. Geosci., 32, 421-433, 2006.

Vahidnia, M. A., Alesheikh, A. A., Alimohammadi, A., and Hosseinali, F.: A GIS-based neuro-fuzzy procedure for integrating knowledge and data in landslide susceptibility mapping, Comp. Geosci., 36, 1101-1114, 2010.

Varnes, D. J.: Slope movements, Types and processes, in: Landslides: analysis and control, edited by: Schuster, R. L. and Krizker, R. J., Spec. Rep. 176, Transp. Res. Board, Nat. Ac. Of Sc., Washington, 1978.

Vieira, J., Morgado, D. F., and Mota, A.: Artificial neural networks and neuro-fuzzy systems for modelling and controlling real systems: a comparative study, Eng. Appl. Artificial Int., 17, 265273, 2004.

Zadeh, L. A.: Information and control, Fuzzy sets, 8, 338-353, 1965.

Zaheeruddin, G.: A neuro-fuzzy approach for prediction of human work efficiency in noisy environment, Appl. Soft. Comput., 6, 283-294, 2006.

Zimmermann, H. J.: Fuzzy set theory and its applications, Dordrecht, Kluwer, 2nd Edn., 1991.

Zweig, M. H. and Campbell, G.: Receiver-operating characteristics (ROC) plots, Clinical Chem., 39, 561-577, 1993. 